\title{
Neighborhood Environment and the Elderly's Subject Well-being
}

Xuhui LIU, Phd candidate, Department of urban planning, Tongji University; China

Yifan YU, Professor, Department of urban planning, Tongji University; China

Xin SUI, Department of urban planning, Tongji University; China

\section{Abstract}

Background:

In the context of an aging society, the physical and mental health and quality of life of the elderly have received more and more attention. Among them, in the field of mental health of the elderly, subject well-being is an important concern.

Many studies have shown that the environment has a certain impact on people's mental health. In the field of landscape, public health and architecture, most of the studies focus on the natural environment, including the number and proportion of green space, the distance to green space, the characteristics of green space, as well as the building density, building form, road network density and layout in the built environment. However, in China, the specific environment elements that are more comprehensive and more closely linked with urban planning and management need to be studied.

Objectives:

Relevant research shows that more than $80 \%$ of the activities of the elderly are completed within $1 \mathrm{~km}$ of the neighborhood. This study takes neighborhood environment as the main research area and research object. The objectives include: 1, to find the status of the elderly's subject well-being in Shanghai; 2, to find the impact of the neighborhood environmental factors on the subject well-being of the elderly; and therefore, 3, to put forward some suggestions for neighborhood planning to promote the subject well-being of the elderly.

Methods:

Based on the data of the Fourth Survey on the Living Conditions of the Elderly in Urban and Rural Areas of China, 3431 urban residential samples in Shanghai were selected and analyzed in this study. The subject well-being comes from the question, "General speaking, do you feel happy?" Options include five levels, ranging from very happy to very unhappy. According to the existing literature and the specific requirements of Shanghai urban planning compilation and management, the environmental factors are summarized as 20 indicators in four aspects: natural environment, housing conditions, urban form and facility environment. According to the sample address, the environmental factors indicators are calculated in GIS. The data are analyzed by the method of path analysis in Mplus7.4.

Results: 
70.9\% of the respondents felt very happy or happy, while only $2.2 \%$ of the respondents said they were unhappy or very unhappy. Non-agricultural household registration, higher education, better self-rated economic status of the elderly, the better of the subject well-being of the elderly. Under the control of the basic characteristics and socio-economic attributes of the elderly, the per capita green space area, housing construction area, road network density and location conditions have a significant impact on the well-being of the elderly.

Conclusion:

Under the control of socio-economic variables, community environment can significantly affect the subjective well-being of the elderly. In the planning of community life circle, improving the level of green space per capita in the community, improving the housing conditions of the elderly, and building a high-density road network system are effective measures to promote the subject well-being of the elderly.

\section{Key words:}

The elderly, Subject well-being, Neighborhood environment.

\section{Background}

\subsection{Ageing is a major challenge for the current society}

In the world, the population is growing rapidly and the trend of aging is spreading rapidly. According to the World Population Outlook issued by the United Nations in 2017, the total population of the world is about 7.6 billion by 2017, of which 910 million people are over 60 years old. With the low fertility, the global aging problem is becoming more and more serious. The report issued by the World Health Organization points out that the impact of population ageing is usually more important than population growth (WHO, 2008). Compared with developed countries, the social and economic development speed of developing countries often fails to catch up with the development speed of population aging (WHO, 2003). Aging has become an important issue facing all countries in the world.

China has entered the stage of rapid aging development. By the end of 2016, the total population of China was 1.374 billion, of which $16.1 \%$ were over 60 years old and $10.5 \%$ were over 65 years old (National Statistical Bureau of the People's Republic of China, 2015). Shanghai has entered an aging society since 1979. According to statistics, as of 2017, the registered population of Shanghai is 483.6 million people aged 60 and above, accounting for $33.2 \%$ of the total population, and 317.67 million people aged 65 and above, accounting for $21.8 \%$ of the total population (Shanghai Aging Science Research Center, 2018). The state and local governments have promulgated relevant policies for the cause of ageing, which provide guidance for the development of the cause of ageing. Paying attention to the elderly, promoting healthy aging and active aging are important issues in urban development.

\subsection{Better well-being of old age is an important goal of the cause of aging}

According to WHO's definition of health, psychological well-being is an important part of the health of the elderly. Under the guidance of healthy aging and active aging, the mental health of 
the elderly is an important goal of our work.

Since Wanner Wilson wrote The Relevant factors of self-reported well-being in 1967, psychological research on well-being has gone through more than 40 years. Well-being is the central issue of philosophy, ethics, economics and sociology. Well-being index is the focus of the government. If GDP (gross domestic product) and GNP (gross national product) are the criteria to measure the wealth of the country and the people, then the Gross National Happiness Index (GNH) is the criterion to measure the happiness of the people, and the wealth of the country is for the happiness of the people and for "creating our happy life" (the conclusion of the report of the 16th National Congress of China, 2002). CCTV put forward slogans such as "Starting towards Happiness" as the expression of "Happiness Fever" at the media level.

\section{Literature review}

\subsection{Subject well-being}

The explanation of well-being in the 1997 edition of Wechsler's English Dictionary is: a good or satisfactory living condition; a state of health, happiness and prosperity.

The study of happiness can be traced back to ancient Greek philosophy. Traditionally, the concept and theory of happiness can be classified into two basic types: hedonic and eudemonia. The hedonic view of "happiness theory" originated from Aristippus's philosophy. The Eudaimonic view of happiness comes from the perspective of Aristotelian school. Aristotle puts forward the view that happiness is the self-realization of human beings, therefore, his theory of happiness is also called perfectionism (Zhang Lu, Zuo Bin, 2007).

Based on different philosophical traditions, there are two orientations in the study of modern well-being: Subjective well-being (SWB) and Psychological well-being (PWB). Subjective well-being develops from the theory of happiness. It pays attention to emotions and life satisfaction. It believes that human happiness is expressed by human emotions. Happiness means satisfaction with life, with more positive emotions and fewer negative emotions (Diener $E$, Eunkook S, Richard L. et al., 1999); and psychological well-being is expressed by reality. The present theory evolves to focus on personal growth, self-acceptance, autonomy, life goals and so on (Zhang Lu, Zuo Bin, 2007).

Diener, an American scholar, put forward in 1984 that subjective well-being refers to the overall assessment of the quality of life of an evaluator according to his own criteria. His research on subjective well-being has a great impact on Chinese scholars (Li Zhi, Xie Chaohui, 2006). Diener (1984) believes that the basic characteristics of subjective well-being are subjectivity, relative stability and integrity.

The well-being of the elderly is not only an important criterion for judging the quality of life of the elderly, but also one of the necessary conditions affecting their physical and mental health. (He Quan, Zhang Shi, Wang Ping, 2015).

A large number of studies have shown that subjective well-being is an important comprehensive psychological index to measure the mental health level and personal quality of life of the elderly (Zhang Wei, Hu Zhongming, Li Hongjuan, 2014). 


\subsection{Influencing factors of subject well-being}

Initial research on objective influencing factors was mainly carried out along the dimensions of demographic projects. Wilson pointed out in his Relevant Factors of Self-proclaimed Happiness that happy people are young, healthy, well-educated, well-paid, religious, married, and intelligent and so on. These projects are considered to be the determinants of happiness. With the deepening of research, many studies have pointed out that objective factors have little explanatory power on well-being. Demographic items (such as gender, income, intelligence level, etc.) can only explain less than $20 \%$ of the changes in well-being, while external environment can only explain $15 \%$ of the changes in well-being (Jin Huihong, Chen Yu, 2012).

It has been found that age is an important factor affecting people's well-being. Many studies have confirmed that happiness decreases with age (Baird, Lucas, \&amp; Donnellan, 2010; Godoy-Izquierdo et al., 2013; Mroczek \&amp; Spiro, 2005). However, some studies have found that the relationship between happiness and age is a U-shaped curve (Lobos et al., 2016). At the same time, from the perspective of gender, there is no significant difference in the overall SWB between men and women. However, gender differences still exist in different dimensions of SWB (Wang Fang, Chen Fuguo, 2006).

A literature review found that happiness is not associated with age, but that it is important to have good social relations as well as be self-confident and extroverted (Ferraz, et al., 2007). Although happiness is a subjective experience, it is related to psychological and socio-cultural traits (Ferraz, et al., 2007), social support, and social engagement in activities outside the family (Seligman, 2003). Social capital and social participation are also important factors (Cooper et al., 2011). Good interpersonal relationships can lead to an increase in positive emotions, and individuals can achieve high happiness (Wang Fang, Chen Fuguo, 2005). Social support and social participation in extra familial activities (Seligman, 2003). Health is also a influencing factor of subject well-being. Nan, et al. (2014) found that the relationship between happiness and mental health was greater than that between physical health. A study found that illness does not directly lead to a decline in happiness, but what matters is the degree to which illness interferes with everyday functions (Angner et al., 2013).

\subsection{The Impact of Environment on Mental Health and Subject Well-being}

Environment refers to the total of natural and artificially modified natural factors affecting human survival and development, including atmosphere, water, ocean, land, mineral deposits, forests, grasslands, wildlife, natural relics, human relics, nature reserves, scenic spots, cities and villages (the Environmental Protection Act of the People's Republic of China, 2015). Natural Environment (NE) is the sum of all kinds of natural factors surrounding people and the material basis for human survival. Built environment refers to all kinds of buildings and places that can be reconstructed by man-made construction, especially those that can be changed by policy and human behavior, including the location and design of residential, commercial, office, school and other buildings, as well as the location and design of pedestrian, bicycle, greenway and road (Handy S L, et al., 2002). Built environment is a combination of a series of elements related to land use, transportation system and urban design. As one of the important factors to promote public physical activity and health, built environment is an important entry point for urban planning to actively intervene in health (Lu Feidong, Tan Shaohua, 2015).

Neighborhood is the main place where people live and the basic unit of a city. Neighborhood 
include hardware elements such as space environment, facility configuration, and software elements such as social humanities. As the basic unit and space carrier of people's living and social interaction, neighborhood is closely related to people's health and well-being (Croucher et al., 2007; Hu Yuting, 2017).

More and more studies have confirmed that the built environment has a significant correlation with people's mental health. Although there are various methods and different conclusions in these studies under different backgrounds, it has become a fact that the environment has an impact on human behavior and other factors, or in a way of direct exposure, affects human mental health.

In conclusion, the environmental factors affecting mental health mainly include the following aspects: green space, housing, density, road network, etc.

\subsubsection{Green space}

A number of research cases showed that the increase in the number of green spaces is conducive to improving people's mental health level and promoting people's health perception. Canadian research shows that increasing tree planting in a city block can improve people's health awareness in a way that is equivalent to an increase in personal income (Omid Kardan et al., 2015). The total number and area of public green space are significantly correlated with better mental health and support dose-response relationship. Providing adequate public green space within local neighborhoods and walking distance is important for positive mental health (Wood, L., 2017).

The proportion of green space is the proportion of the area of green space/green space in a certain range, and green coverage is also used to characterize it. The percentages of green space within $3 \mathrm{~km}$ radius interact significantly with the number of health complaints and perception of general health caused by stressful life events (Agnes E. van den Berg et al., 2010); the areas occupying more than $8 \%$ of the park area are positively correlated with SRH (Parra, D.C., etc., 2010); and those living in neighborhoods with higher percentages of green space are positively correlated with self-reported health (Parra, D.C., 2010). People reported a lower risk of sleep deprivation (Thomas Astell-Burt et al., 2013); people living in urban areas with more green spaces (a high proportion of green spaces) were happier, showing significantly lower mental pain and higher happiness (Mathew P. White, lan Alcock et al., 2013). Characterized by the percentage of green space in the $1 \mathrm{~km}$ buffer zone, the residents in the greenest area had lower risk of psychological distress and less sedentary time than those in the least green area. Interaction between sports activities and green space was observed (Thomas Astell-Burt et al., 2013). Vegetation coverage is positively correlated with the lower prevalence of depression, anxiety and stress. There is a quantifiable relationship between mental health and the natural characteristics of the neighbourhood that people actually experience (Daniel T. C. Cox et al., 2017).

\subsubsection{Density and Road Network}

The density of built environment includes population density and construction density (such as volume ratio, housing density, etc.).

The construction density of the built area within 300 meters of the residential area has a significant correlation with mental health. In the study of Sarah Foster et al. (2010), residential 
density is the ratio of residential area to the number of residential buildings in the service area, and it is one of the constituent indicators of community morphological index. The community morphological index was significantly correlated with the decrease of crime fear.

Street network accessibility is characterized by street sports potential (overtaking volume of street sections) and street connectivity (the number of sections connected to a certain section, i.e. the density of street intersections). Research shows that the reduction of psychological distress is associated with higher accessibility of local street networks ("mobile potential") (Chinmoy Sarkar et al., 2013). Using street connectivity in a 0.5-mile buffer zone as a measure of design, poor street connectivity has a negative impact on life satisfaction [Xinyu (Jason) Cao, 2016].

The number of intersections is also an important indicator of street network. Street connectivity is calculated by the ratio of three-way intersection to total service area. The comprehensive community morphology index is significantly related to the reduction of crime fear. A more walkable community is also a place where residents feel safe (Sarah Foster, 2010). The number of total intersections within the radius of 300 meters around the residential area was significantly correlated with the happiness dimension (Elizabeth J Burton et al., 2011).

\subsubsection{Service facilities}

Australian studies found that, independently of other factors, the higher the degree of land use mixing, the higher the risk of depression (Dick Saarloos, 2011). Retail service availability was associated with a $40 \%$ increase in the risk of depression, regardless of other factors, including other land use. Although local retail stores help walking, this may increase the risk of depression in older men (Dick Saarloos, 2011). The use of cultural facilities is positively correlated with the physical and mental health and subjective well-being of the elderly (Liu, Y., et al., 2017).

\subsubsection{Location}

Residential location is characterized by seven categories: major town centers, major town districts, major town margins, large town centers, large town margins, small towns and villages. Research shows that residential location in urban and rural areas is one of the measures of the constructive environment with the greatest number of significant correlations with health (Elizabeth J Burton, et al., 2011). Mental health is determined by neighbourhood level. Residents living in neighborhoods farther away from the city center tend to have better mental health (Hongwei Dong, Bo Qin, 2017).

Therefore, we can see that environmental factors can be divided into two categories. One is the environmental factors of physical space itself, such as location, green space level and density, road network and other characteristics. On the other hand, it is the environmental factors of service facilities, which represent the public service level of the environment, and service facilities are often based on the physical space environment.

Mathew P. White, et al. (2017) pointed out that although people are increasingly interested in the relationship between natural environment and subjective well-being (SWB), previous studies have various limitations in methodology and theory. Under the background of Shanghai's high-density human settlements and Oriental culture-oriented environment, it is worth discussing the relationship between built environment and mental health, especially with people's subject well-being which has been paid more and more attention. The environmental 
construction towards good subject well-being will be a necessary Supplement for the research in the above-mentioned fields.

\section{Objectives}

Based on the survey data and combined with the existing characteristics of Shanghai's urban planning compilation and management, this paper mainly answers the following questions:

1. The general well-being and distribution characteristics of the elderly in Shanghai at present;

2. Under the control of other variables, does the built-up environment of community affect the well-being of the elderly? What is the impact?

3. What aspects should we pay attention to in the construction of a well-being-oriented community environment?

\section{Methods}

\subsection{Data sources}

Based on the data of the fourth survey on the living conditions of the elderly in urban and rural areas of China (the fourth survey), 3431 urban residential samples in Shanghai were analyzed. The data are sorted in spss22 and analyzed in Mplus7.4 by the method of path analysis.

\subsubsection{Neighborhood Environment}

According to the existing literature and the specific requirements of Shanghai urban planning compilation and management, the environmental factors are summarized as 11 indicators in five aspects: green space, housing conditions, urban form (including building area volume ratio and road network density) facility environment, and location. According to the sample address, the environmental factors indicators are calculated using the GIS platform.

\subsubsection{Subject well-being}

Subject well-being comes from the question in the fourth survey, "In general, do you feel happy?" Options include five levels, ranging from very happy to five very unhappy.

\subsubsection{Control variables}

\section{(1) Gender}

This index data comes from the "the fourth survey" questionnaire. In the "A - basic information" part of the questionnaire, there are questions about "A1- the gender of the elderly interviewed ", " 1 " is male and " 0 " is female.

(2) Age

This index data comes from the "the fourth survey" questionnaire. In the "A - basic information" part of the questionnaire, there is a question "A2 -the age of the interviewed old people". The age of the elderly is divided into six age groups: 1: 60-64 years old, 2: 65-69 years old, 3: 70-74 years old, 4: 75-79 years old, 5: 80-84 years old and above. 
(3) Household Registration

This index data comes from the "the fourth survey" questionnaire. In the "A - Basic Information" section of the questionnaire, there is a question " A3 -What type of household registration do you belong to?" There are three options: "1 agriculture, 2 non-agriculture and 3 unified household registration".

(4) Education

This index data comes from the "the fourth survey" questionnaire. In the "A - basic information" part of the questionnaire, there are six options: "A5 -your educational level", including "1 have not attended school (including literacy classes), 2 primary schools (including private schools), 3 junior middle schools, 4 senior high schools/secondary vocational schools, 5 colleges, 6 undergraduates and above". The higher the value, the higher the educational level of the elderly.

(5) Marital status

This index data comes from the "the fourth survey" questionnaire. In the "A - basic information" section of the questionnaire, there are questions "A8- your current marital status", "1 have a spouse, 2 widow 3 Divorce, 4 never married." The data are arranged as nominal variables, 1 as having a spouse and 0 as having no spouse now.

(6) Economic situation

This index data comes from the "the fourth survey" questionnaire. In the "E- Economic Situation" section of the questionnaire, there is a question, "Which of the following do you think your economic situation belongs to?" There are five choices: "1 very abundant, 2 relatively abundant, 3 basically enough, 4 more difficult, 5 very difficult", The lower the value, the better the self-assessment economic status of the elderly.

\subsection{4. Analytical methods}

(1) GIS (Geographic Information System)

The GIS platform is helpful to calculate the spatial relationship of data and to express it intuitively. It is the basic work platform of this study.

(2) SPSS 22

Data are collated and basic descriptive analysis is carried out.

(3) Mplus 7.4

Path analysis is carried out.

\section{Results}

\subsection{Descriptive analysis}

Table 1 Happiness of the elderly interviewed

\begin{tabular}{|c|l|l|l|l|l|}
\hline \multicolumn{2}{|c|}{} & count & $\begin{array}{c}\text { percentage } \\
(\%)\end{array}$ & $\begin{array}{c}\text { Effective } \\
\text { percentage } \\
(\%)\end{array}$ & $\begin{array}{c}\text { Cumulative } \\
\text { percentage } \\
(\%)\end{array}$ \\
\hline \multirow{3}{*}{ effective } & Very happy & 712 & 20.8 & 20.8 & 20.8 \\
\cline { 2 - 6 } & $\begin{array}{l}\text { Comparatively } \\
\text { happy }\end{array}$ & 1719 & 50.1 & 50.1 & 70.9 \\
\hline
\end{tabular}




\begin{tabular}{|l|l|l|l|l|l|}
\hline & $\begin{array}{l}\text { Generally } \\
\text { happy }\end{array}$ & 921 & 26.8 & 26.9 & 97.8 \\
\cline { 2 - 7 } & $\begin{array}{l}\text { Comparatively } \\
\text { unhappy }\end{array}$ & 60 & 1.7 & 1.7 & 99.5 \\
\cline { 2 - 7 } & Very unhappy & 17 & .5 & .5 & 100.0 \\
\cline { 2 - 7 } & total & 3429 & 99.9 & 100.0 & \\
\hline missing & & 2 & .1 & & \\
\hline total & & 3431 & 100.0 & & \\
\hline
\end{tabular}

The proportion of the elderly who choose "relatively happy", "general" and "very happy" is the highest. More than half of the elderly feel "relatively happy", and only $2.2 \%$ feel "relatively unhappy" and "very unhappy".

\subsubsection{Population differences}

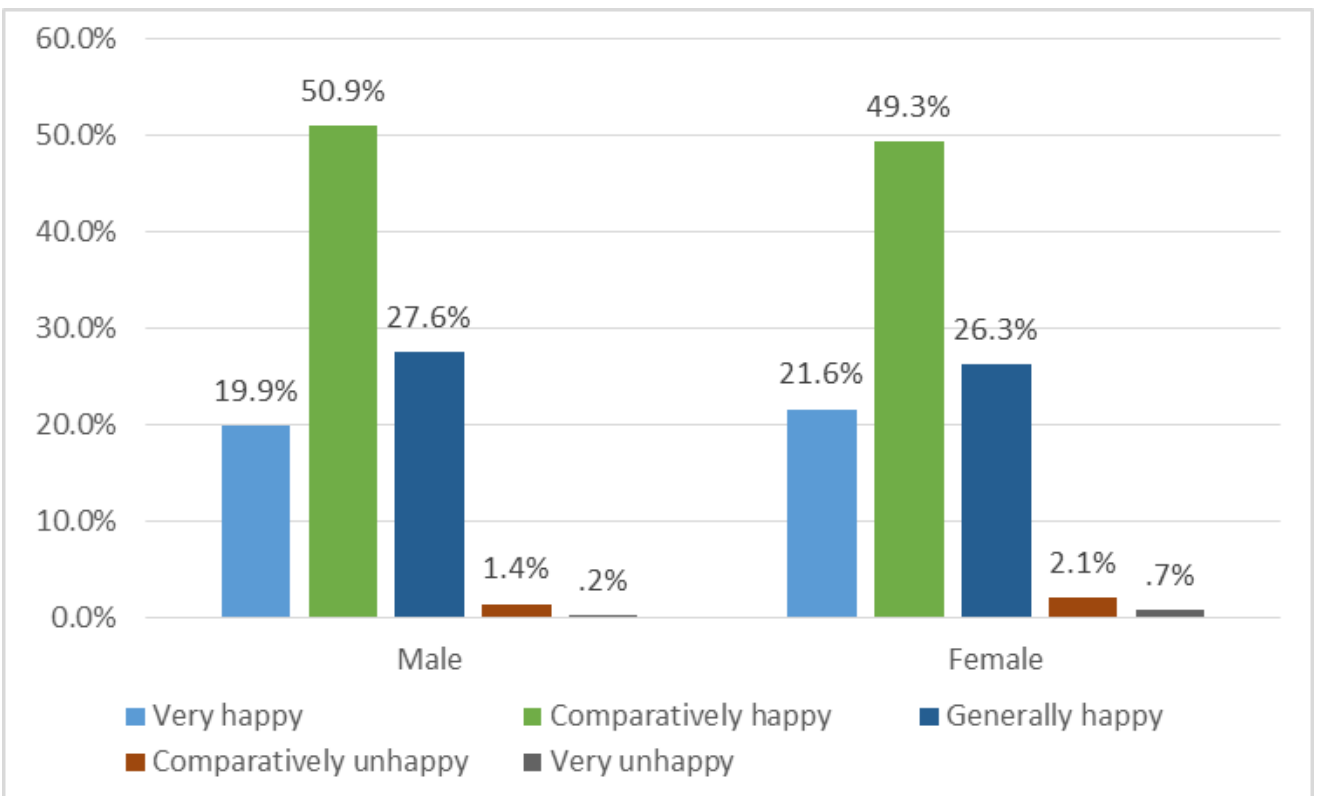

Figure 1 Differences in happiness among the elderly interviewed by different genders 


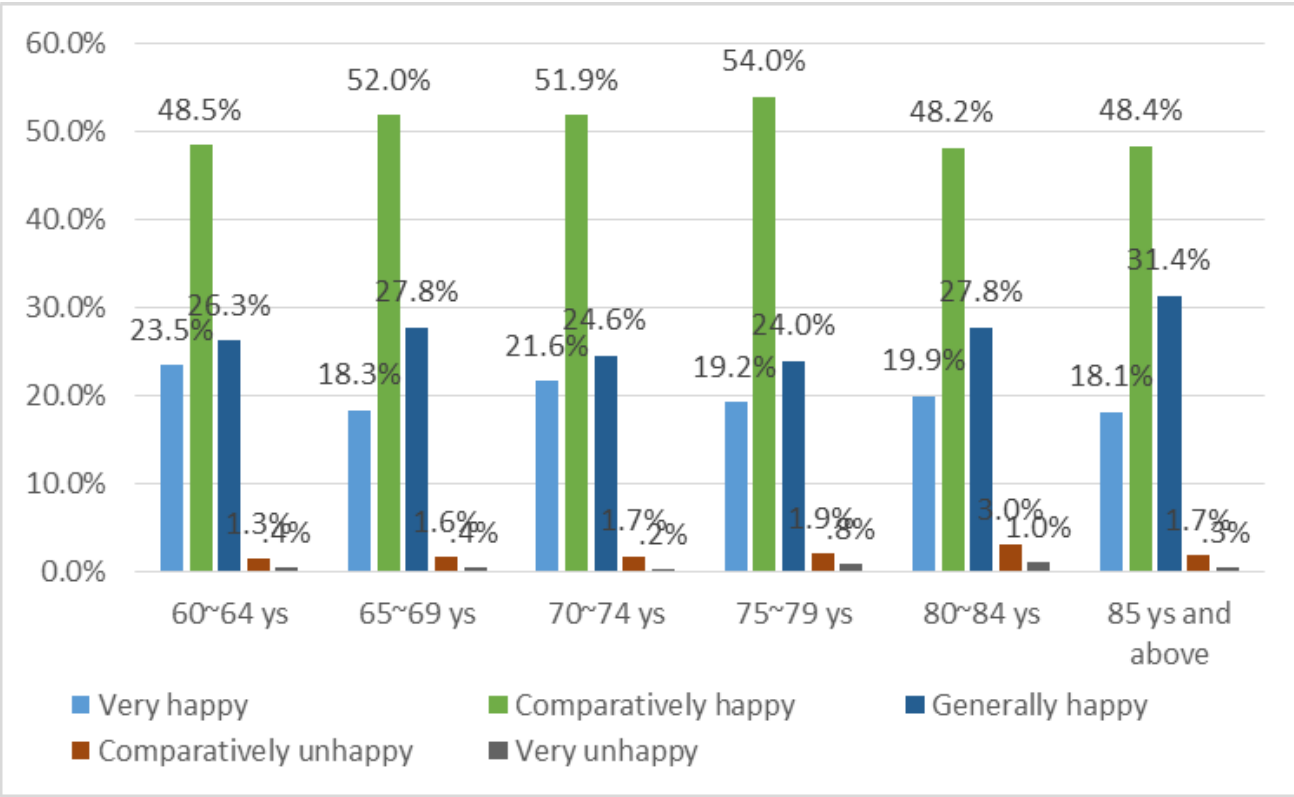

Figure 2 Differences in happiness among the elderly interviewed at different ages

There is no significant difference in happiness between men and women. There was no significant difference in happiness among the elderly of all ages.

\subsubsection{Regional differences}

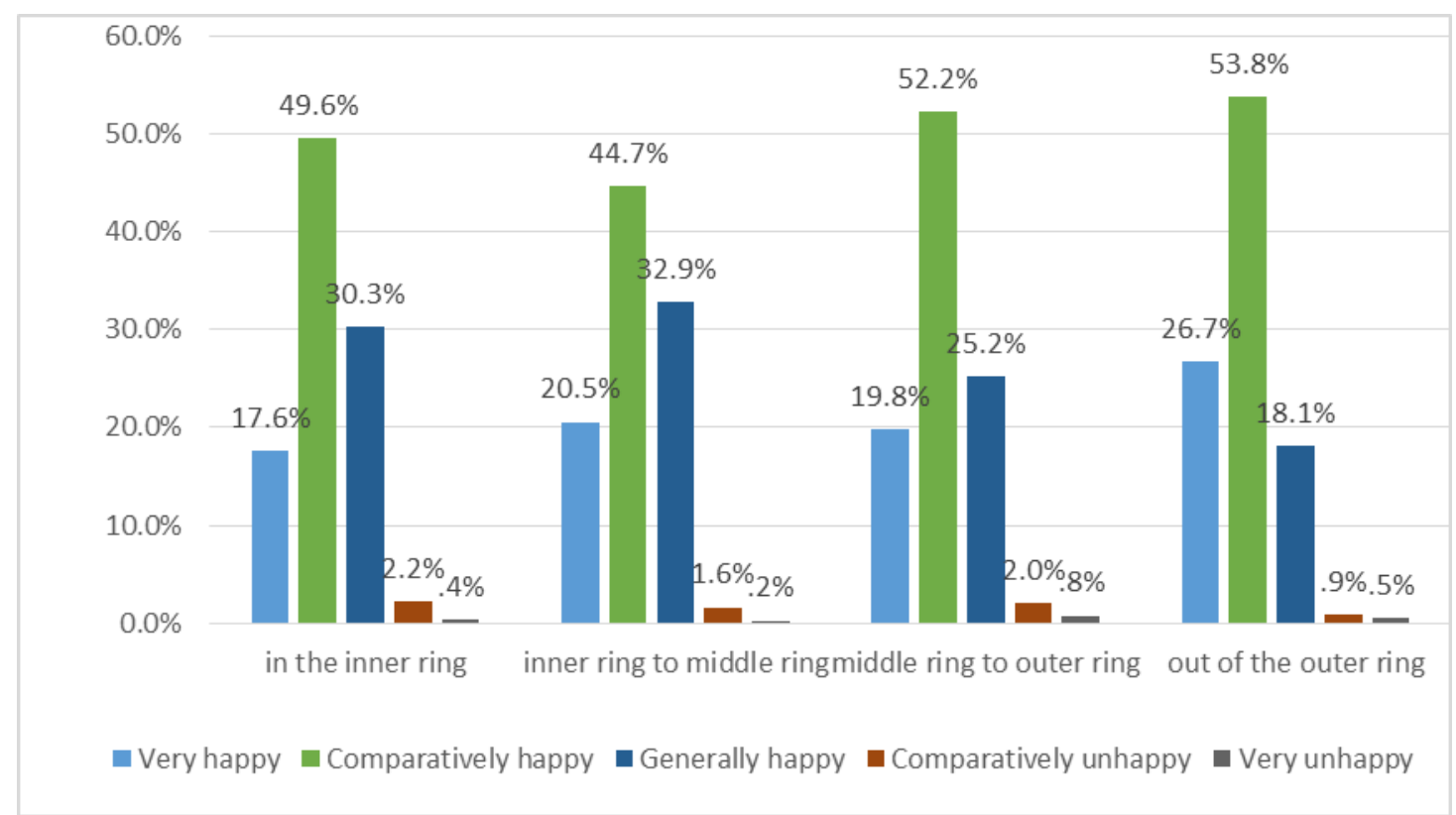

Figure 3 Regional differences in happiness among the elderly interviewed

There were significant differences in happiness among the elderly in different regions (Sig < 0.001). The proportion of "very happy" and "relatively happy" old people outside the central city is higher than that in the central city; the proportion of "general" and "relatively unhappy" old people is lower than that in the central city; the proportion of "very unhappy" old people is $0.2 \%-0.8 \%$, and there is no significant difference in different regions. 
5.2. The impact of community environmental factors on the well-being of the elderly

\subsubsection{Impact of green space, housing and urban form}

Table 2 Model 1

\begin{tabular}{|l|l|l|l|l|}
\hline $\begin{array}{l}\text { The Influencing Elements of } \\
\text { Happiness }\end{array}$ & Estimate & S.E. & Est./S.E. & P-Value \\
\hline Gender & -0.025 & 0.016 & -1.535 & 0.125 \\
\hline Age & 0.023 & 0.018 & 1.302 & 0.193 \\
\hline Household register & $-\mathbf{0 . 0 9 1}$ & $\mathbf{0 . 0 1 7}$ & $\mathbf{- 5 . 3 3 1}$ & $* * *$ \\
\hline Marital status & -0.03 & 0.018 & -1.683 & 0.092 \\
\hline Education & $\mathbf{0 . 1 4 8}$ & $\mathbf{0 . 0 1 8}$ & $\mathbf{8 . 2 5}$ & $* * *$ \\
\hline Self-reported economic status & $\mathbf{- 0 . 3 1 4}$ & $\mathbf{0 . 0 1 8}$ & $\mathbf{- 1 7 . 8 1 1}$ & $* * *$ \\
\hline Proportion of green space area & 0.01 & 0.018 & 0.562 & 0.574 \\
\hline Per capita green space area & $\mathbf{0 . 0 5 5}$ & $\mathbf{0 . 0 1 7}$ & $\mathbf{3 . 2 4 8}$ & $\mathbf{0 . 0 0 1} * *$ \\
\hline Housing area & $\mathbf{0 . 0 9 9}$ & $\mathbf{0 . 0 1 8}$ & $\mathbf{5 . 4 5 4}$ & $* * *$ \\
\hline Housing type & 0.03 & 0.016 & 1.894 & 0.058 \\
\hline Volume ratio & 0.013 & 0.017 & 0.753 & 0.451 \\
\hline Road network density & 0.018 & 0.02 & 0.906 & 0.365 \\
\hline Location(Distance to downtown) & $\mathbf{0 . 0 7 6}$ & $\mathbf{0 . 0 2 4}$ & $\mathbf{3 . 1 8 1}$ & $\mathbf{0 . 0 0 1} * *$ \\
\hline
\end{tabular}

Among personal characteristics, household registration, educational level and self-assessment of economic status have significant effects on the well-being of the elderly. Non-agricultural household registration, older people with higher education level, and older people with better self-assessment of economic status, have higher happiness.

From the point of view of material space environment factors, the per capita green space area, housing construction area and distance to the city center have a significant impact on the well-being of the elderly. The more green space per capita and housing construction area per capita, the higher the happiness of the elderly. From the location of the elderly, the farther away from the city center, the happier the elderly are.

\subsubsection{Impact of public facilities}

Table 3 Model 2

\begin{tabular}{|l|l|l|l|l|}
\hline $\begin{array}{l}\text { The Influencing Elements of } \\
\text { Happiness }\end{array}$ & Estimate & S.E. & Est./S.E. & P-Value \\
\hline Gender & -0.024 & 0.017 & -1.472 & 0.141 \\
\hline Age & 0.028 & 0.018 & 1.613 & 0.107 \\
\hline Household register & $-\mathbf{0 . 0 8 9}$ & $\mathbf{0 . 0 1 7}$ & $-\mathbf{5 . 2 3 7}$ & $* * *$ \\
\hline Marital status & -0.028 & 0.018 & -1.539 & 0.124 \\
\hline Education & $\mathbf{0 . 1 4 8}$ & $\mathbf{0 . 0 1 8}$ & $\mathbf{8 . 2 3 8}$ & $* * *$ \\
\hline Self-reported economic status & $\mathbf{- 0 . 3 1 1}$ & $\mathbf{0 . 0 1 8}$ & $\mathbf{- 1 7 . 6 7 2}$ & $* * *$ \\
\hline Proportion of green space area & 0.014 & 0.018 & 0.776 & 0.438 \\
\hline
\end{tabular}




\begin{tabular}{|l|l|l|l|l|}
\hline Per capita green space area & 0.034 & 0.018 & 1.86 & 0.063 \\
\hline Housing area & $\mathbf{0 . 1 0 4}$ & $\mathbf{0 . 0 1 9}$ & $\mathbf{5 . 5 8 6}$ & $* * *$ \\
\hline Housing type & 0.027 & 0.016 & 1.619 & 0.106 \\
\hline Volume ratio & 0.011 & 0.017 & 0.625 & 0.532 \\
\hline Road network density & $\mathbf{0 . 0 5 8}$ & $\mathbf{0 . 0 2 7}$ & $\mathbf{2 . 1 3 1}$ & $\mathbf{0 . 0 3 3}$ \\
\hline Location(Distance to downtown) & $\mathbf{0 . 0 8 8}$ & $\mathbf{0 . 0 2 5}$ & $\mathbf{3 . 5 2 9}$ & $* * *$ \\
\hline Number of public service facilities & -0.025 & 0.029 & -0.865 & 0.387 \\
\hline Medical distance & 0.003 & 0.017 & 0.152 & 0.879 \\
\hline Number of transport facilities & -0.043 & 0.026 & -1.655 & 0.098 \\
\hline Distance of traffic facilities & 0.018 & 0.018 & 1.049 & 0.294 \\
\hline
\end{tabular}

After adding the facility environment variables, we found that besides the significant impact of personal characteristics in model 1 on the well-being of the elderly, the per capita green space area, housing construction area and distance to the city center are still the significant factors affecting the well-being, but the per capita green space area is no longer significant, and the density of road network has also become a significant environmental factors. As far as the environmental factors of facilities are concerned, there is no significant correlation between the number of public service facilities, medical distance, the number of transportation facilities and the distance to transportation facilities and the well-being of the elderly.

\section{Discussion}

\subsection{Personal characteristics and the subject well-being of the elderly}

Previous studies have consistently confirmed that individual socioeconomic attributes have a significant impact on mental health (Claire Dujardin et al., 2014; Becky P. Y., Loo et al., 2017; Hongwei Dong, Bo Qin, 2017), and that in the process of environmental impact on mental health, there are differences among different populations in the process of environmental impact.

The household registration system has an important impact on the distribution of people's resources and living opportunities, and has become the most important parameter to depict the inequality of China's social structure (Zheng Bingdao, Wu Xiaogang, 2013). Studies have confirmed that household registration has an important impact on people's political, economic and professional status (Lu Yilong, 2008). Using the survey data from 2010 to 2013, Li Wenjie and Luo Yuhui (2016) found that the social stratum structure of the agricultural household registration population has obvious physical labor characteristics. Agricultural household registration holders are far less likely to enter the management class or even the non-manual labor class than Non-peasant household registration holders. Due to the difference of social resources obtained by household registration, the physical health and mental health of the elderly with different household registration will be affected. In this study, household registration has a significant impact on the subject well-being of the elderly. The elderly with agricultural household registration have a worse sense of happiness than those with non-agricultural household registration. 
Similarly, the educational level has a certain impact on the occupational and economic status of the elderly and the corresponding social resources. Studies have also confirmed that education has an important impact on health (Hu Guangyu, Duojun, 2010). In this study, educational level has a significant positive impact on the well-being of the elderly. The higher the educational level, the better the subject well-being of the elderly.

Previous studies have found that income level, education level, social stratum and social network all have an impact on the health of the elderly at a significant level of 1\% (Liu Changping, Wang Lianjie, 2017). Economic status has a significant impact on the mental health of the elderly (Yang Benfu et al., 1999; Ning Ziheng et al., 2001; Tangdan, 2010; Hu Guangyu, et al., 2010; Zhang Xia, Yang Yifan, 2017). Like previous studies, economic status has a significant positive impact on the well-being of the elderly. The better the economic situation is, the happier the elderly will be. Economic status is one of the most important factors affecting the health and well-being of the elderly.

\subsection{Green space and the subject well-being of the elderly}

Green space is an important environmental factor in existing research. The quantity of green space is a very important and common environmental measure index. However, in the existing studies, few studies have linked the number of green space with the number of population, considering the per capita green space occupancy level under different population densities. From this perspective, green space is measured and the impact of the environment on human health is analyzed.

In the process of analysis, in terms of the number of green space, considering only the green space density represented by the proportion of green space area, there is no significant correlation between the number of green space represented by the proportion of green space area in community life circle and the physical health and mental health of the elderly.

Further in-depth analysis of the current situation of green space distribution in Shanghai shows that the proportion of green space in the studied neighborhoods has a slight downward trend from the city center to the periphery. Although the spatial distribution of green space is relatively balanced in the city center and the periphery, considering the distribution of population, from the perspective of per capita index, the distribution of green space in the city obviously still has great differences. According to the population density of each research neighborhood and the calculation of the per capita green space area, the research community from the city center to the periphery shows a significant trend of gradual increase, that is, from the city center to the periphery, the per capita green space area enjoyed by the per capita is increasing. From the per capita index, the per capita green space level in the suburbs is significantly higher than that in the central city. From the perspective of the whole city, the per capita green space level of each community is more than 100 times different, and only from the per capita green space level of each community in the central city, the per capita green space value is 10 times different.

In this study, the proportion of green space has no significant impact on the health of the elderly. While combined with the analysis of per capita green space index, we find that per capita green space area is significantly related to the subject well-being of the elderly. Compared with the spatial distribution, per capita green space area is a more effective indicator to promote the mental health of the elderly.

Therefore, for green space, it is not enough to consider the balance of spatial distribution. More 
importantly, it is to match the population distribution in order to better integrate with the actual needs of people. Only by combining with human needs and serving as the basis of spatial layout, can we better and more effectively play its internal functions and achieve the original purpose and goal of planning.

\subsection{Housing Conditions and the subject well-being of the elderly}

Existing studies have shown that good quality of housing and neighborhood environment and safe social environment are the main reasons for the improvement of subjective and physical health of the elderly (Liu, Y., 2017). Living in Low-Rise housing, better living conditions and healthy physical and social environment have a significant impact on positive mental health (Ghuncha Firdaus, 2017).

Path analysis shows that housing area has a significant positive impact on the subject well-being of the elderly when controlling the basic socio-economic attributes of the elderly and considering the impact of all built-up environmental factors such as community location. Housing construction area reflects the quality of housing conditions for the elderly. Meanwhile, the larger building area is related to the larger number of people living together (Sig. $=0.010$ ), which is conducive to reducing the loneliness of the elderly and improving their mental health.

Relevant analysis shows that there is no significant correlation between the housing conditions of the elderly and their self-reported economic status. Therefore, it can be said that housing conditions are independent of economic status and have a significant positive impact on the subject well-being of the elderly themselves.

\subsection{Road network density and the subject well-being of the elderly}

Studies have confirmed that high road network density has a positive impact on mental health [Chinmoy Sarkar et al., 2013; Xinyu (Jason) Cao, 2016]. High-density road network design is often associated with more diverse functional layouts and promotes walking opportunities for the elderly to their destinations, thereby enhancing their social participation and physical activity. Considering the facility environment data at the same time, the analysis of this study shows that the consistency with the above study, road network density has a significant role in promoting the subject well-being of the elderly.

\subsection{Location and the subject well-being of the elderly}

Location has a significant impact on the elderly's subject well-being. This is consistent with the above descriptive, that is, the elderly in the periphery of the central city are significantly better than those in the central city in terms of subject well-being.

Location reflects the difference of population distribution. At the same time, location also determines the characteristics of various elements of built environment. At the same time, location also reflects different social and economic conditions.

\subsection{Facility Environment and the subject well-being of the elderly}

There are small number of researches that take public facilities directly as an independent variable to analyze the relationship between environment and health. However, the number of public facilities is often related to the diversity of land use and road network density. The higher the diversity of land use within the community, the more public facilities. Land use diversity has been shown to have a significant impact on mental health. For example, although the overall 
impact of land use combination is not significant, it also has a positive and negative impact on life satisfaction (Xinyu (Jason) Cao, 2016). The higher the degree of land use mixing, the higher the risk of depression (Dick Saarloos, 2011). Previous study (Zhu Weijue, 2010) has also showed that medical distance has a significant positive impact on the health of the elderly. The nearer the medical distance, the better the physical health performance of the elderly.

In this study, land use mixing degree was not directly measured, but in terms of the number of public facilities, medical distance, transport facilities and transport facilities distance, these facility environmental variables were not significantly related to the well-being of the elderly.

\section{Conclusion}

Based on the sample of elderly people in Shanghai, this study explored the relationship between neighborhood built environment and elderly's subject well-being. The path analysis in the structural equation model shows that the household registration, educational level and self-assessment of economic status of the elderly can significantly affect the well-being of the elderly. Under the condition of controlling the basic social and economic attributes of the elderly, some neighborhood environmental factors have significant effects on the happiness of the elderly, including per capita green space area, housing building area and distance to the city center. When the environmental variables of facilities are added, the influence of green space is not significant, and the density of road network has a significant positive impact on the well-being of the elderly.

This study of the elderly in Shanghai is consistent with the existing research conclusions, which confirms the positive effect of green space on mental health, as well as the significant impact of road network density, housing conditions and location (distance to the city center). From the perspective of community construction, improving the per capita green area index, increasing the density of road network and improving housing conditions will be conducive to enhancing people's happiness.

\section{References}

[1] ED, Diener; et al. (1999) "Subjective well-being: three decades of progress", Psychological Bulletin, Vol. 2 No. 125(March).

[2] ED, Diener; et al. (2000) "New direction in Subjective well-being research: the cutting edge", Indian Journal of Clinical Psychology, No. 27.

[3] ED, Diener(2000)"subjective Well -Being -The science of Happiness and Proposal for National Index", American Psychologist, Vol 55, No. 1.

[4] Miao, Yuanjiang (2009) "Happiness Index in Development", Nanjing Social Science, No. 11 (November).

[5] Duan, Jianhua (1996) "Summary of Subjective Well-being", Psychological Dynamics, Vol. 4 No. 01.

[6] Zhang, Lu; Zuo, Bin (2007) "Self-fulfilling Happiness: A Review of Psychological Well-being 
Research" Progress in Psychological Science, Vol. 15 No. 01 (January).

[7] Li, Zhi; Xie, Chaohui (2006) "Literature Review on Subjective Well-being in China" Journal of Chongqing University (Social Science Edition), Vol. 12 No. 4 (August).

[8] He, Quan; Zhang, Shi; Wang, Ping (2015) "The Impact of Community Management on the Well-being of the Elderly in the Construction of 'Livable Community for the Elderly': A Case Study of Hangzhou", Northwest Population, Vol. 36 No. 4 (April).

[9] Zhang, Wei; Hu, Zhongming; Li, Hongjuan (2014) "Influencing factors of subjective well-being of urban elderly", Population and development, Vol. 20 No. 6 (December).

[10] Jin, Huihong; Chen, Yu (2012) "A Study on Happiness and Professional Happiness", Modern Marketing: Xueyuan Edition, No. 10 (October).

[11] Pedro, Konsesan; Romina, Bandero; Lu, Yanhua (2013) "Literature Review of Subjective Well-being", Overseas Theoretical Dynamics, No. 7 (July).

[12] Nan, H; et al. (2014) "Psychometric evaluation of the Chinese version of the subjective happiness scale: Evidence from the Hong Kong family cohort", International Journal of Behavioral Medicine, Vol. 21 No. 4 (April).

[13] Seligman, M. E. (2003) “Positive psychology: Fundamental assumptions”, Psychologist, Vol. 16 No. 3 (March).

[14] E., Angner; J., Ghandhi; K. Williams Purvis; D. Amante; J. Allison (2013) "Daily functioning, health status, and happiness in older adults", Journal of Happiness Studies, Vol. 14 No. 5 (October).

[15] Bruna, Moretti Luchesi; et al. (2018) "Factors associated with happiness in the elderly persons living in the community", Archives of Gerontology and Geriatrics, No. 74 (October).

[16] Wang, Fang; Chen, Fuguo (2006) "Influencing factors of subjective well-being", Chinese Behavioral Medicine Science, Vol. 14 No. 6 (June).

[17] L, Handy S; Boarnetmg; R, Ewing; et al. (2002) "How the built environment affects physical activity: Views from urban planning", American Journal of Preventive Medicine, Vol. 23 No. 2S (August).

[18] Lu, Feidong; Tan, Shaohua (2015) "Research on the Impact of Built Environment on Physical Activities: Progress and Reflection", International Urban Planning, Vol. 30 No. 2 (April).

[19] K, Croucher; L, Myers; R Jones; et al. (2007) "Health and the physical characteristics of urban neighborhoods: A critical literature review", Glasgow: Glasgow Centre for Population Health.

[20] Yu, Yifan; Hu, Yuting (2017) "International Research Progress on the Impact of Community Building on Environmental Health: Literature Review and Consideration from the Perspective of Physical Activity", Journal of Architecture, No. 2 (February).

[21] Kardan, Omid; et al. (2015) "Neighborhood greenspace and health in a large urban center", Scientific Reports, Vol. 5 No. 1 (July).

[22] L., Wood; et al. (2017) "Public green spaces and positive mental health - investigating the relationship between access, quantity and types of parks and mental wellbeing", Health \& Place, Vol. 48 (November).

[23] E. Agnes; et al. (2010) "Green space as a buffer between stressful life events and health", Social Science \& Medicine, Vol. 70 No. 8.

[24] D.C., Parra; et al. (2010) "Perceived and objective neighborhood environment attributes and health related quality of life among the elderly in Bogotá, Colombia", Social Science \& 
Medicine, Vol. 70 No. 7 (April).

[25] Astell-Burt, Thomas; Feng, Xiaoqi; Kolt, Gregory S. (2013) "Mental health benefits of neighbourhood green space are stronger among physically active adults in middle-to-older age: Evidence from 260,061 Australians”, Preventive Medicine, 2013. 57(5): 601-606.

[26] White, Mathew P.; Alcock, Ian; Wheeler, Benedict W.; Depledge, Michael H. (2013) "Would You Be Happier Living in a Greener Urban Area? A Fixed-Effects Analysis of Panel Data", Psychological Science, Vol. 24 No. 6 (April).

[27] Cox, Daniel T. C.; et al. (2017) "Doses of Neighborhood Nature: The Benefits for Mental Health of Living with Nature", BioScience, Vol. 1 NO.2 (January).

[28] Foster, Sarah; et al. (2010) "Neighbourhood design and fear of crime: A social-ecological examination of the correlates of residents' fear in new suburban housing developments", Health \& Place, Vol. 16 No. 6 (November).

[29] Sarkar, Chinmoy; Gallacher, John; Webster, Chris (2013) "Urban built environment configuration and psychological distress in older men: Results from the Caerphilly study", BMC Public Health, No. 13 (December).

[30] Cao, Xinyu (Jason) (2016) "How does neighborhood design affect life satisfaction? Evidence from Twin Cities", Travel Behaviour and Society, Vol. 5 (September).

[31] Burton, Elizabeth J; Mitchell, Lynne; Stride, Chris B (2011) “Good places for ageing in place: development of objective built environment measures for investigating links with older people's wellbeing”, BMC Public Health, No. 11 (December).

[32] Liu, Y., et al. (2017) "Healthy urban living: Residential environment and health of older adults in Shanghai", Health \& Place, Vol. 47 (September).

[33] Dong, Hongwei; Qin, Bo (2017) “Exploring the link between neighborhood environment and mental wellbeing: A case study in Beijing, China", Landscape and Urban Planning, Vol. 164 (August).

[34] Dujardin, Claire; Lorant, Vincent; Thomas, Isabelle (2014) "Self-assessed health of elderly people in Brussels: Does the built environment matter?", Health \& Place, Vol. 27 (May).

[35] Loo, Becky P. Y.; Lam, Winnie W. Y.; Mahendran, Rathi; Katagiri, Keiko (2017) "How Is the Neighborhood Environment Related to the Health of Seniors Living in Hong Kong, Singapore, and Tokyo? Some Insights for Promoting Aging in Place", Annals of the American Association of Geographers, Vol. 107 No. 4 (July).

[36] Zheng, Bingdao; Wu, Xiaogang (2013) “Hukou,'Agricultural to Non-Agricultural' and income inequality among urban residents in China", Sociological Research, Vol. 28 No. 1 (January).

[37] Lu, Yilong (2008) “Does household registration still work - household registration system and social stratification and mobility", China Social Science, No. 1 (January).

[38] Li, Wenjie; Luo, Yuhui "Social Stratum Structure Analysis under Urban and Rural Household Registration System - Based on 2010-2013 CGSS Data", Jianghan Academy, Vol. 35 No. 5 (October).

[39] Yang, Benfu; Liu, Dongguang; Shao, Guangfang (1999) "Jining City, the status of elderly depression and its influencing factors", Chinese Journal of Gerontology, No. 4 (February).

[40] Ning, Ziheng; et al. (2001) "Investigation and analysis of depressive symptoms and their influencing factors among the elderly in Macao", Chinese Journal of Mental Health, No. 5 (May). 
[41] Zhang, Xia; Yang, Yifan (2017) "Research on the Influencing Factors of Mental Health of Middle-aged and Elderly People in China - Empirical Analysis Based on CHARLS Data", Vol. 5 No. 2 (February).

[42] Wang, Hong; et al. (2005) "Research progress on psychosocial factors of geriatric depression", Geriatrics and health care, Vol. 11 No. 3 (June).

[43] Tang, Dan; Zou, Jun; Shen, Jiliang; Zhang, Ling (2006) "Influencing factors of subjective well-being of the elderly", Chinese Journal of Mental Health, Vol. 20 No. 3 (March).

[44] Liu, Changping; Wang, Lianjie (2017) "Study on the influence of socioeconomic status on the health status of the elderly", Population Science of China, Vol. 37 No. 5 (October).

[45] Firdaus, Ghuncha (2017) "Built Environment and Health Outcomes: Identification of Contextual Risk Factors for Mental Well-being of Older Adults”, Ageing International, Vol. 42 No. 1 (March).

[46] Zhu, Weijun (2015) "Social Capital and Aging Health: An Empirical Study Based on the Comprehensive Survey Data of Shanghai Communities", Social Sciences, No. 5 (May). 